\title{
Reproductive health care in the postnatal period in Guatemala
}

Erika Jacobs

Carlos Brambila

Ricardo Vernon

Population Council

Follow this and additional works at: https://knowledgecommons.popcouncil.org/departments_sbsr-rh

Part of the Demography, Population, and Ecology Commons, International Public Health Commons, Maternal and Child Health Commons, and the Public Health Education and Promotion Commons How does access to this work benefit you? Let us know!

\section{Recommended Citation}

Jacobs, Erika, Carlos Brambila, and Ricardo Vernon. 2002. "Reproductive health care in the postnatal period in Guatemala," FRONTIERS Final Report. Washington, DC: Population Council. 


\title{
Reproductive Health Care in the Postnatal Period in Guatemala
}

\author{
Erika Jacobs \\ Carlos Brambila \\ Ricardo Vernon
}

August 5, 2002

This study was funded by the U.S. AGENCY FOR INTERNATIONAL DEVELOPMENT (USAID) under the terms of Cooperative Agreement Number HRNA-00-98-00012-00 and Population Council in-house project Number 580013006426. The opinions expressed herein are those of the authors and do not necessarily reflect the view of USAID. 


\section{GUATEMALA: REPRODUCTIVE HEALTH CARE \\ IN THE POSTNATAL PERIOD}

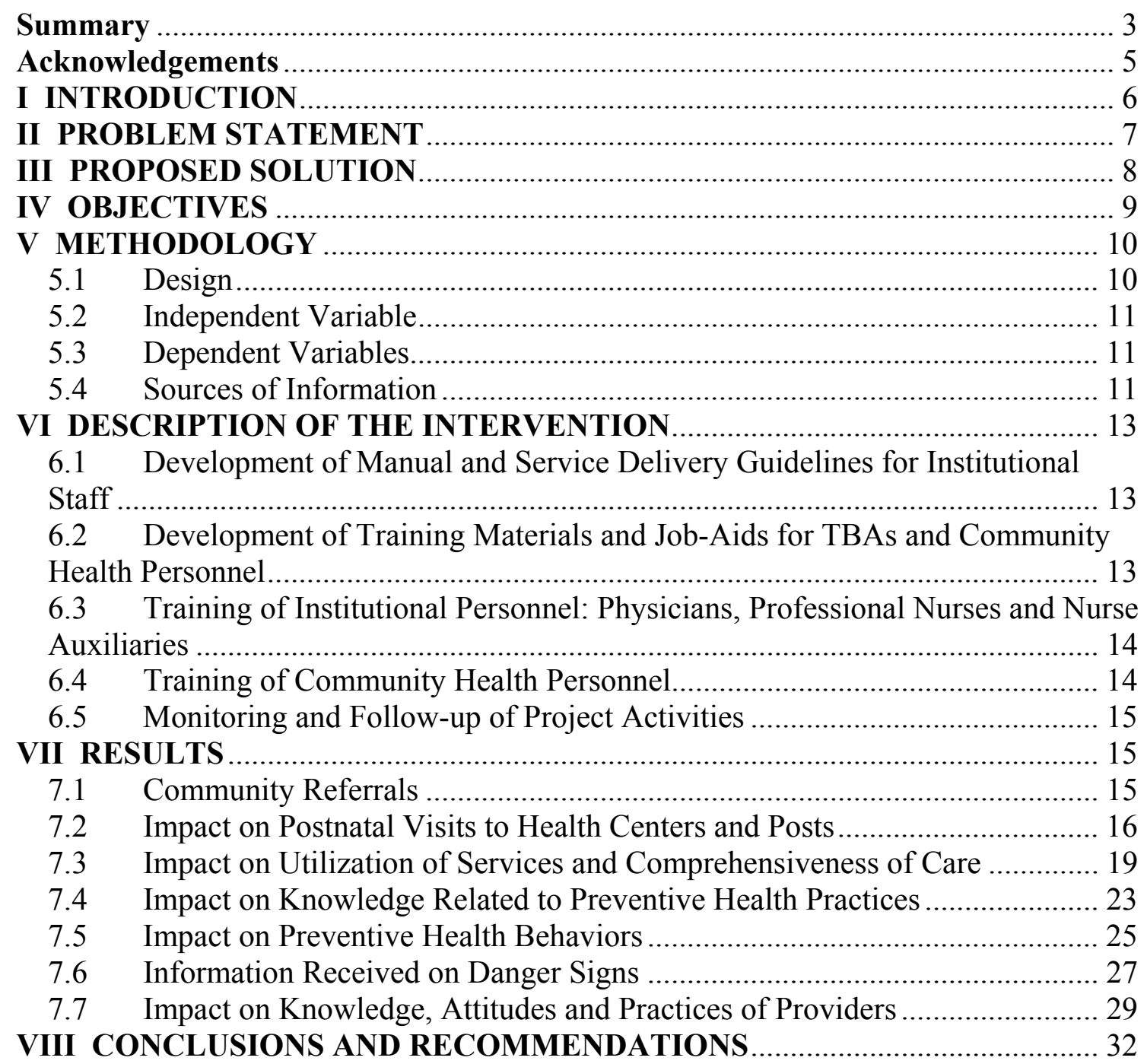




\section{GUATEMALA: REPRODUCTIVE HEALTH CARE IN THE POSTNATAL PERIOD}

\section{Summary}

The problem that this operations research addressed was how to increase the proportion of women in Guatemala who receive postnatal care. The study aimed to develop and test a job aid to provide comprehensive care to mothers and children during the first year postpartum, to train physicians, nurses, auxiliary nurses and social workers in its use, and to develop and test strategies and materials for training community health agents to promote services for new mothers during the first year postpartum. It also collected data to establish if these strategies were effective in improving the quality and comprehensiveness of the care received by mothers and children less than one year of age.

This project developed high quality training manuals for both the primary and secondary levels of care, developed IEC materials to provide adequate postpartum information and services to mothers and families, trained 56 institutional service providers at health centers and posts, including eight doctors, seven nurses, and 41 nurse auxiliaries; and trained 385 community health workers, including 212 TBAs and 173 volunteer promoters.

Concerning impact on services offered at institutional facilities, service statistics show that the number of postnatal visits increased 46 percent in experimental sites over the 18 month project period, the ratio of postpartum visits over prenatal visits increased 2.7 times, and the ratio of postpartum visits over registered births increased 1.5 times. However, statistics show similar trends among the control group with a one-month or more lag. This suggests contamination of the control group, the confounding effect of other interventions such as training conducted by the Calidad en Salud program, or that the intervention only influenced the timing but not the decision to seek care.

Drawing from exit interviews, the intervention appeared to be successful increasing the likelihood that women receive preventive services when they attend health facilities, in particular family planning services, increasing the range of services received by both mothers and babies during postnatal visits, and providing more information about danger signs for the mother and the baby. However, there were no significant changes in the amount of actual information provided to women, the quality of the services received by each mother at health facilities, service providers' knowledge about danger signs, or preventive behaviors recommended by service providers.

Regarding contraceptive use, the proportion of women using a method three months after birth increased from 18.1 percent in the baseline in the experimental group to 24.7 percent in the endline, compared to a decrease from 20.4 to 14.3 percent in the control group. Very importantly, the proportion of women starting use of contraceptives during the puerperal period (less than 40 days) increased from 3.1 to 15.6 percent in the experimental group, while it remained approximately constant in the control group at 10.0 percent. The proportion of women using contraceptives after the puerperal period and before three months postpartum increased from 6.9 percent to 19.4 percent among 
the experimental group and reduced from 23.0 to 15.4 percent in the control group. These changes are statistically significant.

A survival analysis shows that about one-fourth of those using contraceptives began using their method in the first month after birth. By the second month, 58.8 percent of the current contraceptive users were already using a method, and by the third month 70.1 percent had requested a method. By the fifth month postpartum, 84.8 percent of contraceptive users were already using the method, and at six months, 90.2 percent had adopted the method. No significant changes were observed between periods and groups.

Results also showed that a greater proportion of women sought preventive services for themselves in the experimental group than in the control group, and that services received by women at intervention sites were more diverse than at control sites.

Several factors may account for these results: (1) possible contamination of the control group, due to communication between experimental and control service providers, (2) confounding effects of other interventions implemented during the twoyear period, (3) length of the time span between training of institutional service providers and the actual evaluation, and (4) overall changes in the management and structure of the primary health care level in Guatemala. 


\section{Acknowledgements}

The project was implemented in the Department of Quetzaltenango. The executing organization was the Area Headquarters of the $\mathrm{MOH}$ and the principal investigator was Dr. Ericka Jacobs. In 1999, when this project was started, the Head of the Quetzaltenango Health Area was Dr. Anabella Aragon, who was replaced by Dr. Ismael Chan on March 2000. The designated health area staff members were Dr. Vilma Villatoro and M. Nora Judith Rodas.

The original idea of this project was developed by Ricardo Vernon, who also supervised the development of the postpartum care manual for institutional personnel. The initial manual and guides were reviewed by a technical team of physicians both in Guatemala and Mexico. In Guatemala, materials were reviewed by Dr. Ericka Jacobs and Dr. Vilma Villatoro of MSPAS. In Mexico, the manual was reviewed by Dr. Vicente Diaz.

Workshop organizers included Dr. Anabella Aragon, Head of the Quetzaltenango Health Area, Dr. Vilma Villatoro and M. Nora Judith Rodas, Health Area staff, and Drs. Carlos Brambila, Silvia Llaguno, Ericka Jacobs, FRONTIERS staff. The workshop implementation manual was developed by Dr. Clara Arango from Mexico, and was adapted and modified by FRONTIERS project staff to be used at the start of project workshop.

On August 22, 2000, Dr. Ismael Chan, the new Health Area Head at the time, called for a project evaluation meeting. During this meeting, Drs. Brambila and Jacobs presented progress made in training and results achieved to date. Each district was able to discuss progress made and present problems encountered during project implementation. This initiative strengthened the intervention and prompted further interest from Health District doctors and personnel. 


\section{GUATEMALA: REPRODUCTIVE HEALTH CARE IN THE POSTNATAL PERIOD}

\section{INTRODUCTION}

The first days, weeks and months after a birth comprise a period of substantial reproductive health information and service needs for both mother and child. Given the greater mortality risks in the first weeks postpartum, service providers should be able to detect any infection or hemorrhage (in Bangladesh, for example, about $60 \%$ of maternal deaths and $50 \%$ of infant deaths occur in the first six weeks postpartum) ${ }^{\mathrm{i}}$. During this period, mothers begin to breastfeed and confront the main obstacles that often lead to abandonment of this practice; thus, many have a need for support and information. Given blood loss during childbirth and delivery, and the nutritional demands of breastfeeding, postpartum women often require nutritional complements, especially vitamin $\mathrm{A}^{\mathrm{ii}}$, iron, folic acid, calcium and zinc ${ }^{\text {iii }}$. It has also been observed that during this period, that women may be at greater risk of being victims of violence (particularly intimate partner violence), and to suffer depression and stress; therefore counseling services should be made available ${ }^{\text {iv }}$. In the first six months after a birth, the organs of women slowly return to the pre-pregnancy state and in the first six weeks, the involution of the uterus occurs. In the months following, the woman begins to ovulate, and is again exposed to the possibility of pregnancy; thus there is a need to provide information on contraceptive methods and their use to avoid unwanted or risky pregnancies. Finally, at the end of the sixth month, there is a need to complement the baby's nutrition with other foods in addition to breast milk, so the mother should receive information on the introduction of solid and semi-solid foods and, eventually, about weaning.

The delivery of family planning services is particularly important, since it has been shown that a new pregnancy within 18 to 24 months substantially increases the morbidity and mortality risks of both mothers and children. In addition, a recent study of 27 DHS-III surveys by Ross and Winfrey ${ }^{\mathrm{v}}$ shows that among women within a year of their last birth, two-thirds have unmet need for contraception and that nearly 40 percent plan to use a method but have not done so. In fact, a third of all unmet need for contraception falls among women who had a birth in the previous year.

Even though there is consensus on the advisability of providing information on contraceptive methods during prenatal care or, failing this, as soon after the birth as possible, there are different opinions about the best moment to begin the use of contraception postpartum ${ }^{\mathrm{vi}}$. Some experts recommend the provision of contraceptive methods at the first opportunity postpartum, since a woman may not return for another visit. Others, however, recommend that women exclusively breastfeed and begin using a method upon the return of ovulation or at six months postpartum, whichever occurs first. To avoid an unwanted pregnancy, women not breastfeeding exclusively should begin using a method no later than six weeks after the birth of the child. In all cases, a well-informed woman should make the decision on whether to use a method or not, and when to start using it.

In terms of the use of contraception in the postpartum period, in the absence of contraindications and a woman's preference for a specific method, the intrauterine 
device (IUD), local methods, and progestin-only hormonal methods (including pills, the injectable and subdermal implants) are preferred. In the case of hormonal methods with estrogen, however, most authors recommend against beginning use of the method until the sixth week postpartum. The use of combined hormonal contraceptives is not recommended because they decrease the production of breast milk.

For the newborn, in addition to appropriate nutrition during the first year (particularly, exclusive breastfeeding in the first six months and the introduction of other foods afterwards), the main focus of health systems should be to provide essential immunizations and to supervise respiratory or diarrheal infections. In Guatemala, for example, the immunization schedule recommended by the $\mathrm{MOH}$ is the following ${ }^{\mathrm{vii}}$ :

Table 1

Child Immunization Schedule Recommended by the MOH in Guatemala

\begin{tabular}{|l|c|c|c|}
\hline Vaccine & 1st Dose & 2nd Dose & 3rd Dose \\
\hline BCG & At birth & - & - \\
\hline DPT & At two months & One month later & One month later \\
\hline Poliomyelitis & At birth & At two months & - \\
\hline $\begin{array}{l}\text { Measles } \\
\text { Tetanus } \\
\text { Toxoid }\end{array}$ & $\begin{array}{c}\text { Fetween nine and } 12 \\
\text { months }\end{array}$ & - & - \\
\hline
\end{tabular}

From a public health perspective, the importance of the postnatal period as a strategic moment for providing reproductive health services is well recognized. The service delivery guidelines of Guatemala, Honduras, Mexico and Nicaragua ${ }^{\text {viii }}$, for example, recommend: (1) the provision of information on nutrition and hygiene, and nutritional complements, (2) thorough examination to identify any possible infection, anemia and/or hemorrhage, (3) the provision of education on and support for breastfeeding, care of the newborn, family planning, emotional changes and registration of the child in the vital registration system. In addition, a few guidelines recommend that the mother receive additional services after the sixth week postpartum, such as screening for sexually transmitted diseases and Pap smears.

\section{PROBLEM STATEMENT}

Despite the strategic importance of the postpartum period as an opportunity for providing a wide range of preventive reproductive and child health services, most countries show a very low rate of return to postpartum care at health service delivery units. Program managers and researchers have offered a number of reasons for this phenomenon, including the priority attention that women often give to their children's health over their own, their mistrust of public health services, a perception of low 
service quality, cultural beliefs regarding the need to stay at home during the first 40 days after a birth, and low perceived value for postnatal health and care.

Even though lack of accessibility to services has been offered as a reason for low attendance to postpartum services, service statistics usually show that these visits are almost always substantially fewer than visits for prenatal care, well baby care or immunization services. In Guatemala, about 50 percent of pregnant women seek prenatal care, nearly 60 percent of children have complete immunization schedules ${ }^{\text {ix }}$, but only an estimated 15 percent of women receive postnatal care. A similar coverage of services is observed in the different departments in the country. For example, in Quetzaltenango, service statistics for October 1998 showed prenatal care coverage of 50 percent, child immunization coverage of 80 percent and postpartum visit coverage of 9 percent $^{\mathrm{x}}$. These data show that many women who seek other services at public health centers do not seek postnatal care.

These data also suggest that a large proportion of women and children have limited or no contact with $\mathrm{MOH}$ services, either because they receive services from other providers (mostly traditional community health agents), or because they do not have access to any kind of health care. Thus, the problem that this operations research addressed was how to increase the proportion of women in Guatemala who receive postnatal care.

\section{PROPOSED SOLUTION}

To increase the proportion of women who receive postnatal care in Guatemala, the following strategies were pursued:

\section{A) To increase the proportion of women who return to postpartum services among those who are in contact with MOH health services}

There is a large proportion of women who are already clients of reproductive health services at $\mathrm{MOH}$ outlets but who, for a variety of reasons, do not receive postpartum care. Perhaps the most productive strategy to increase the proportion of women who receive care would be to change service delivery practices to accomplish this. This may include:

1) Developing protocols and job-aids for postpartum care which are consistent with $\mathrm{MOH}$ norms and increase the perceived and/or objective content value of postpartum visits by increasing the number and type of services offered during the visit, and to train service providers in their use.

2) Identifying women with unmet need for postpartum care among those attending the health facility, and providing them the service. This might include systematically screening the needs of women in contact with services such as well baby care and immunization, and linking postpartum and maternal-child care services.

3) Increasing the saliency and perceived value of postpartum care among women who attend services and are likely to need the service in the near future, i.e. 
underline and explain the importance and contents of postnatal care services among women attending prenatal care.

B) To establish a strong referral system for women in the postpartum period between traditional community health providers and MOH health providers

As illustrated in a previous section, a large proportion of women in Guatemala have very limited contact or no contact at all with institutional $\mathrm{MOH}$ health service providers. However, these women either use community health providers, or are within their reach, and have contact with $\mathrm{MOH}$ health agents during out-reach activities such as vaccination campaigns. Thus, to increase the proportion who make at least one postpartum care visit to an $\mathrm{MOH}$ health provider, the following strategies were used:

1) Training community health agents so that they can visit women who have had a birth a few days or weeks ago and refer them either to emergency or preventive postpartum health services offered by the $\mathrm{MOH}$. This requires the development of protocols and job-aids.

2) Training $\mathrm{MOH}$ service staff who are in contact with the community to promote postpartum health visits among those who might benefit from them.

\section{OBJECTIVES}

The general objective of this project was to test strategies to increase the proportion of women receiving health services in the first year after the birth of a child, and to increase the comprehensiveness of postnatal care.

Specific objectives of this operations research project were the following:

1) To develop and test a job aid to provide comprehensive care to mothers and children during the first year postpartum, and to train physicians, nurses, auxiliary nurses and social workers in its use.

2) To develop and test strategies and materials for training community health agents to promote services for new mothers during the first year postpartum.

3) To collect data to establish whether these strategies are effective in improving the quality and comprehensiveness of the care received by mothers and children less than one year of age. 


\section{METHODOLOGY}

\subsection{Design}

This project was conducted in 14 health districts in Quetzaltenango ${ }^{\mathrm{xi}}$, a Western department in the highlands of Guatemala. An experimental design with measurements before and after the intervention was used, as follows:

RA

Experimental Group1

Control Group

\begin{tabular}{lrr}
$\gg>>>$ & Time & $>>>>>$ \\
\hline 01 & $X 1$ & 02
\end{tabular}

03
04

Where RA represents the random assignment of health districts to the different conditions; 01 and 03 represent the measurements prior to the intervention; 02 and 04 represent the measurements following the intervention; and X1 the interventions conducted in the experimental group (training with supervised practice in the use of protocols and job aids).

A three-step process was used to assign the districts to the experimental and control groups: First, districts were stratified in four groups according to their geographical location and the number of yearly births registered. This stratification allowed differentiation between indigenous (highlands) and non-indigenous (low lands) districts, and between those districts with high and low service volumes. Second, within each subgroup, districts were randomly assigned to two treatment groups (Group A and Group B). A random number between 1 and 2 was selected for each district: units with random number 1 were assigned to group $A$ and units with random number 2 were assigned to group B. Finally, a random number was assigned for groups A and B to select the experimental and the control groups.

Table 2 presents the districts according to their characteristics and group:

Table 2

Districts Participating in the Operations Research Project by Group, Location and Number of Births Attended

\begin{tabular}{|l|c|c|c|c|}
\hline \multirow{4}{*}{ LOCATION } & \multicolumn{4}{|c|}{ NUMBER OF BIRTHS PER YEAR/ GROUP } \\
\cline { 2 - 5 } & \multicolumn{3}{|c|}{ Less than 2,000 } & \multicolumn{2}{c|}{$\mathbf{2 , 0 0 0}$ or More } \\
\cline { 2 - 5 } & EXPERIMENTAL & CONTROL & EXPERIMENTAL & CONTROL \\
\hline Highlands & Salcaja & San Martín & Cabricán & Quetzaltenango \\
& Zunil & Sija & Onuan \\
& Sibilia \\
& Palestina & & & \\
\hline Lowlands & El Palmar & Flores & Colomba & $\begin{array}{c}\text { Genova } \\
\text { Coatepeque }\end{array}$ \\
\hline
\end{tabular}




\subsection{Independent Variable}

The independent variable was the training of institutional and volunteer health providers in the use of project materials, as described in section VI, description of the intervention.

\subsection{Dependent Variables}

The dependent variables measured were the following:

1) Number of women receiving care during the first six months postpartum, and the proportion of women receiving prenatal care who return for a postpartum consultation.

2) Proportion of women receiving appropriate education and who have in the first six-months postpartum information about: lactation, immunizations, acute respiratory infections, diarrhea and oral rehydration, family planning, and danger signs and symptoms during the puerperal period.

3) Type of care received by women in the six months postpartum: proportion of women receiving services for the opportune detection of cancer, diagnosis and treatment of sexually transmitted diseases, lactation, family planning, percentage of lost opportunities for providing preventive reproductive health services which are available in the health center or post.

4) Knowledge, attitudes and practices of health care providers at institutional facilities regarding integrated health.

5) Proportion of mothers who bring their children under seven months to some service, and who are also assessed, and services given to those assessed.

\subsection{Sources of Information}

The following sources of information were used:

\section{MOH information system}

The MOH's daily register of consultations collects information on the number of prenatal and puerperal consultations. This information is presented in the Monthly Health Statistics Report, which health centers and posts present to the Area Head and which permitted an approximation of the proportion of women who receive prenatal care and return for postnatal care.

\section{Baseline and endline exit interviews of women in the first six months postpartum}

Exit interviews of women in the first year postpartum were conducted before and after the interventions in all experimental and control group health centers and in 
one health post that depended of each center. In both surveys, the interviewers remained in each service delivery outlet for a total of five days, during which they asked all women of reproductive age leaving the center if they had given birth in the last 12 months. They were interviewed regarding the services they had received, the type of care, etc. The same questionnaire was used in both surveys.

Table 3 presents the number of interviews completed in the baseline and endline surveys. A total of 1,465 interviews were conducted in both surveys, 837 in the baseline survey and 628 in the endline survey. Close to 80 percent of the interviews were conducted in health centers. Nearly two-thirds of the interviews in both surveys were conducted in the experimental group, both in the baseline and in the endline.

Table 3

Number of Exit Interviews of Women in the First Year Postpartum by Group, Survey and Type of Health Facility

\begin{tabular}{|c|c|c|c|c|c|c|}
\hline \multirow{3}{*}{$\begin{array}{l}\text { TYPE OF } \\
\text { HEALTH } \\
\text { FACILITY }\end{array}$} & \multicolumn{4}{|c|}{ GROUP } & \multirow{2}{*}{\multicolumn{2}{|c|}{ TOTAL }} \\
\hline & \multicolumn{2}{|c|}{ Experimental } & \multicolumn{2}{|c|}{ Control } & & \\
\hline & Baseline & Endline & Baseline & Endline & Baseline & Endline \\
\hline $\begin{array}{l}\text { Health } \\
\text { Center }\end{array}$ & 408 & 299 & 279 & 200 & 687 & 499 \\
\hline $\begin{array}{l}\text { Health } \\
\text { Post }\end{array}$ & 130 & 101 & 20 & 28 & 150 & 129 \\
\hline Total & 538 & 400 & 299 & 228 & 837 & 628 \\
\hline
\end{tabular}

Regarding the characteristics of the women interviewed, they were predominantly young: 16.7 percent were adolescent mothers between 14 and 19 years of age, and an additional 31.5 percent were between 20 and 24 years of age. About 48 percent of them had one or two children, and 26 percent had three or four. Fifty-seven percent declared that they knew how to read and write, 34 percent had not attended school, and 42 percent had incomplete primary schooling. In both surveys, 95 percent of the women interviewed were married or in union. No significant differences between the baseline and endline samples were found when a Chi square test was used to compare the distributions of these variables.

\section{Baseline and endline surveys of service providers}

During the fieldwork visit to the health centers, all health service providers were interviewed to assess their knowledge, attitudes and practices regarding the services provided to mothers and their children in the first year postpartum.

Table 4 presents the number of interviews conducted in the baseline and endline surveys by type of provider interviewed. In the baseline, 72 providers were interviewed compared to 82 in the endline survey. The baseline assessment included 39 interviews at experimental sites and 22 at control sites. During the endline survey, 53 providers were interviewed at experimental sites and 29 at control sites. About 18 percent of the interviewees were physicians, 14 percent were nurses, and the remaining two-thirds were nurse auxiliaries. There were some variations in the before and after surveys, but these are not statistically significant, so the samples are comparable. 
Table 4

Number of Service Providers Interviewed by Group, Survey and Type of Provider

\begin{tabular}{|l|c|c|c|c|c|c|}
\hline \multirow{2}{*}{$\begin{array}{l}\text { TYPE OF } \\
\text { PROVIDER }\end{array}$} & \multicolumn{4}{|c|}{ GROUP } & \multicolumn{2}{c|}{} \\
\cline { 2 - 7 } & \multicolumn{2}{|c|}{ Experimental } & \multicolumn{2}{c|}{ Control } & \multicolumn{2}{c|}{ TOTAL } \\
\hline Physician & 8 & 8 & 6 & 6 & 14 & 14 \\
\hline Nurse & 7 & 7 & 4 & 4 & 11 & 11 \\
\hline $\begin{array}{l}\text { Nurse } \\
\text { Auxiliary }\end{array}$ & 24 & 38 & 23 & 18 & 47 & 56 \\
\hline Total & 39 & 53 & 33 & 28 & 72 & 81 \\
\hline
\end{tabular}

These health agents provided general consultations, child sickness, prenatal and postnatal visits, well child care, vaccinations and family planning. Only 25 percent of providers, mostly physicians and nurse auxiliaries, reported that they attended deliveries. Respondents attended a mean of 22.5 consultations or visits per day, with physicians attending a mean of 25.5 visits, nurses 19.6 visits and nurse auxiliaries 22.3 visits per day. No changes in these averages were found between the baseline and endline surveys. Over one-half of these (12.5) are visits of children under one year of age per day, 55.7 percent of the total services provided.

\section{DESCRIPTION OF THE INTERVENTION}

\subsection{Development of Manual and Service Delivery Guidelines for Institutional Staff}

The first project activity was the development, pretesting and printing of a manual and of service delivery guidelines that specify the care that should be provided to mothers and children during the first year postpartum. These materials are organized according to four stages of the extended postpartum period: the first 24-hours after the birth, day 2 to 7 after birth, day 7 to 40 after birth, and day 41 to 12 months postpartum. The manual provides step-by-step clinical and counseling guidelines. Each section describes how to identify and deal with complications, and what information and recommendations should be given to the mother, her husband and other family members. The manual and guidelines are consistent with the Guatemala $\mathrm{MOH}$ norms, and those of other Central American countries.

\subsection{Development of Training Materials and Job-Aids for TBAs and Community Health Personnel}

Two materials were developed, pretested and printed for the intervention in the communities. The first is a manual for TBAs and community health agents with 10 charts, five with drawings explaining danger signs and risks, and five with drawings explaining the recommendations that women in each of the four stages of the extended postpartum period should be given. The second is a manual for nurse auxiliaries explaining how to train TBAs and community health agents in the use of the materials and in the implementation of project activities. 
In addition, during the implementation of project activities, two additional IEC materials were produced: leaflets inviting mothers to attend postnatal consultations at health centers were produced for use during vaccination campaigns and posts; and signs were placed at health centers and posts inviting mothers of children under one year of age to receive postnatal care.

\subsection{Training of Institutional Personnel: Physicians, Professional Nurses and Nurse Auxiliaries}

Physicians and nurses were trained in a three-day workshop and nurse auxiliaries were trained in two-day workshops. In addition, both received on-the-job training.

The three-day workshop for physicians and nurses was conducted between February 28 and March 1, 2000. Twenty-two service providers attended the workshop, including eight doctors, eight nurses, three health auxiliaries and one social worker. During the workshop, relevant $\mathrm{MOH}$ service delivery guidelines were discussed and project objectives, materials and concepts were presented and discussed. Workplans for implementing the institutional and community strategies were prepared.

Three workshops were conducted during March and April 2000 to train nurse auxiliaries, social workers and rural health technicians at the intervention health districts. Training included presentations and discussions of the concept and practice of joint mother-child care, and of project objectives, strategies and materials.

In-service training was conducted between May and October 2000 by Dr. Ericka Jacobs, the project's principal investigator, and two regional supervisors trained by Dr. Jacobs. Fifty-six service providers were trained, including eight doctors, seven nurses and 41 nurse auxiliaries. During these visits, at least five consultations of children under one year of age and their mothers were observed using a checklist that summarized project recommendations, and the results were discussed with the providers. Written recommendations were also given to each provider at the end of the visits, to be able to compare with observations during the following visit.

\subsection{Training of Community Health Personnel}

Eight nurses and 40 nurse auxiliaries from intervention health districts received training on the concept of mother-child care during the first year postpartum, identification of danger signs in mothers and babies, and on how to refer mothers and children to institutional health facilities. This was accomplished through one-day workshops held in each participating district in September 2000. Training also included topics on how to involve the communities in project activities, $\mathrm{MOH}$ norms regarding community volunteer health promoters, principles of adult education and how to get across key messages, use of the community postpartum IEC materials, and how to train community health workers. I addition, a training program for community health agents was developed.

Training of community health agents was conducted between October 2000 and June 2001. The objective of this training was to encourage community volunteers to refer women in need of preventive or emergency health services (such as health education, immunizations, family planning, infections or life-threatening hemorrhages) 
to health centers and posts. Training was provided in five sessions, including one introductory session on danger signs for mother and baby during the postpartum period and on how to organize an emergency plan, and one session per each postpartum interval (Day 1 after birth, Day 2 to 7 after birth, Day 8 to 40 after birth and Day 41 to 12 months postpartum). In each session, danger signs, possible complications, their solutions, and what to recommend in terms of preventive practices were discussed. In total, 385 community health workers (of about 500 who were identified) were trained, including 212 TBAs and 173 volunteers.

\subsection{Monitoring and Follow-up of Project Activities}

Health District and Area nurses and nurse auxiliaries, and the project's principal investigator conducted continuous supervisory visits during the period November 2000 to June 2001. During these visits, supervisors reviewed project activities, assessed the knowledge and skills of participating community workers, and provided on-site training to overcome any deficiencies they observed.

\section{RESULTS}

\subsection{Community Referrals}

One of the main project objectives was to increase the proportion of women who attend the health centers and posts in the first year after a birth. To achieve this, community health agents, such as traditional birth attendants (TBAs) and community health volunteers, were trained and asked to identify and visit women who were pregnant or had a child less than one year of age, to provide them with essential health information, and to motivate them to visit the health centers and posts to receive valuable services and information to help them and their babies preserve their health.

About 45 percent of the women interviewed in the baseline and endline surveys in experimental and control group health centers and posts received prenatal care services from TBAs. Women were asked if during these visits, the TBA had recommended a visit to the health center or post for a mother and baby check-up. Results showed that the proportion of women in the experimental group referred during prenatal care by TBAs increased from 62.6 percent in the baseline to 69.5 percent in the endline survey, compared to a change in the control group from 52.5 percent to 76.8 percent. In addition, women were asked if other community volunteers had visited them during their pregnancy, and if they had referred them to a health center for a postpartum check-up. The results showed that only about seven percent of the women had been visited by community health volunteers during their pregnancies, and that in 77 percent of these visits, the promoter had recommended visiting the health center after the birth of the child. No significant differences were found between periods and groups.

All women were asked in the exit interviews if any of the different health agents, such as physicians, nurses, nurse auxiliaries, promoters, volunteer promoters or TBAs, had visited them after their deliveries. Although a significant increase (from $57.8 \%$ to $62.8 \%$ ) was observed in the experimental group in the proportion of women who said they had received such a visit, in the control group an even larger increase was observed 
between the baseline and endline surveys (from $41.1 \%$ to $56.2 \%$ ). Most of the increase was due to more visits by TBAs and $\mathrm{MOH}$ health auxiliaries.

About 70 percent of women interviewed at experimental group health centers, and about 50 percent of the women in the control group facilities had their deliveries attended by a TBA. Prior to the intervention, 62.6 percent of women attended by TBAs in the experimental group reported that the TBA had recommended that she visit to attend medical facilities after the birth. Although this fraction increased to 69.5 percent after the intervention, an even larger and statistically significant increase was observed in the control group, from 52.5 percent to 76.8 percent

Visits by other community agents, such as volunteer health promoters, were not frequent and did not increase between the baseline and endline surveys. It should be mentioned that these visits usually took place several weeks after the birth of a child. The proportion of women who were visited by a health agent in the first 40 days was about 12 percent, with no significant differences found between groups and periods. However, the proportion who were visited in the first three months postpartum increased from 19.8 percent to 24.1 percent in the experimental group and from 15.6 percent to 25.9 percent in the control group, a significant change in both groups.

The mean number of postnatal visits for all women was 1.7 visits per woman. In the experimental group, the mean number of postpartum visits increased from 1.37 to 2.31 , whereas in the control group the increase was from 1.46 to 2.27 , both statistically significant changes.

\subsection{Impact on Postnatal Visits to Health Centers and Posts}

Several proxy variables were used to evaluate if the objective to increase the proportion of women who receive postnatal health services was achieved. The first was the number of postpartum visits reported in the service statistics produced by the $\mathrm{MOH}$. The principal investigator collected this information in monthly visits to the health facilities that participated in the project. Graph 1 shows that during the intervention period, the volume of services increased substantially in the experimental group health outlets. During this period, the number of postnatal visits increased 46 percent with respect to the corresponding period in the year 2000, and this increase became noticeable immediately after the intervention took place. However, the number of postnatal visits in the control group also increased, with a one-month lag, which suggests contamination of the intervention in control group health or the confounding effect of other interventions conducted by the Calidad en Salud program. 


\section{Graph 1}

Number of Registered Postnatal Visits per Treatment Group Quetzaltenango, Guatemala: Jan 1999-Dec 2001

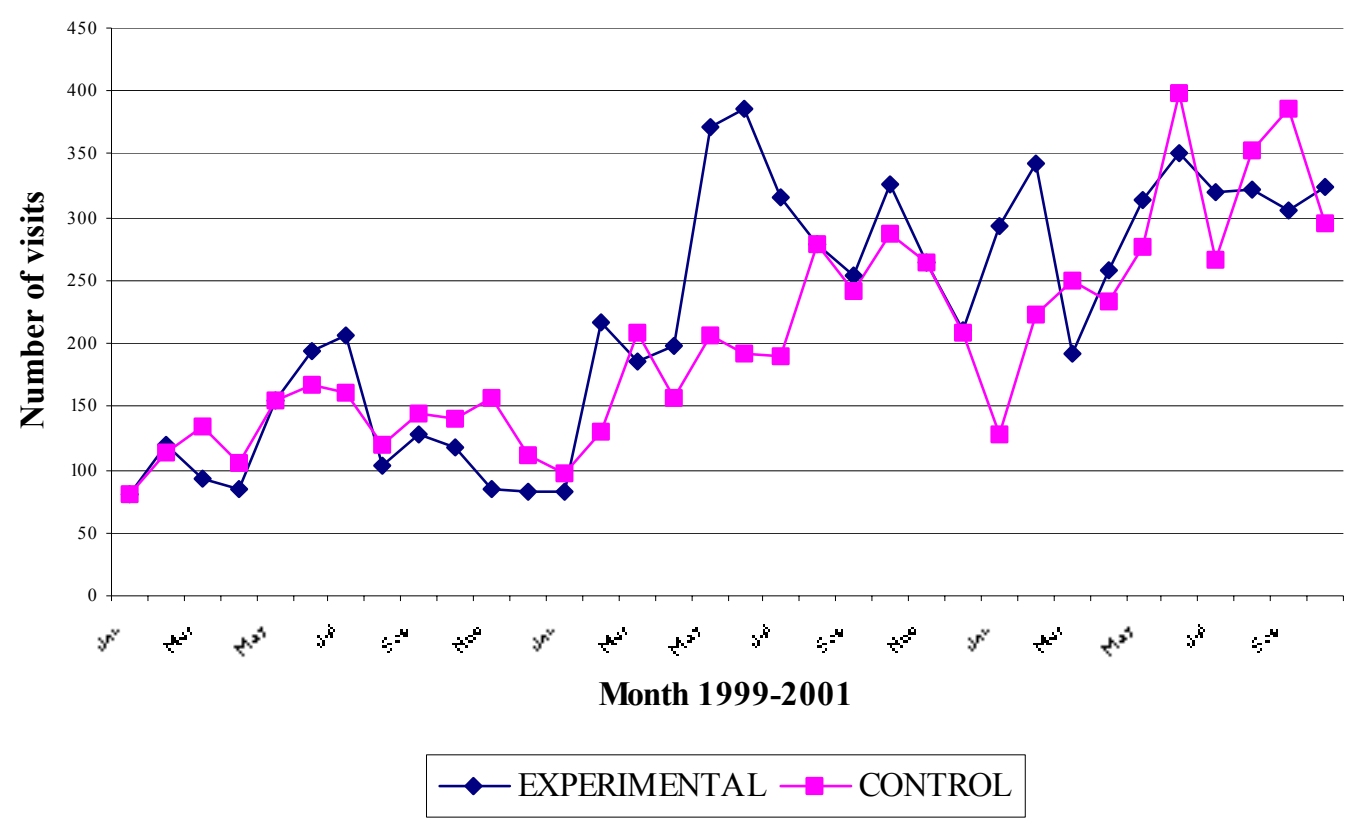

Source: Institutional service statistics. MSPAS, SIGSA 6:1999-2001, provided by the Quetzaltenango Health Area.

The $\mathrm{MOH}$ registers as postnatal visits those occurring during the first six weeks after the birth of a child, and thus, it is not a very good indicator to measure the degree to which the project achieved the objective of increasing the proportion of women who receive preventive care services in the first year after the birth of a child. To better assess the proportion of women who returned to the health center, two additional indicators were derived from service statistics: the number of postnatal consultations over the number of prenatal consultations, and the number of postnatal visits over the total number of registered children born during the same period. These indicators are presented by group and quarterly period of each year.

Graph 2 shows that the ratio of postpartum visits over prenatal visits increased from .16 in January 1999 to .61 in December 2001 in the experimental group, showing a greater tendency for women to return for postpartum visits at institutional medical units. A seasonal pattern may be observed with a tendency to decline in the last quarter of each year. The ratio of postpartum visits/prenatal visits increased from .20 before the initiation of this project to .45 at the end of the project in control sites. 


\section{Graph 2}

Postpartum Visits/ Prenatal Visits per Treatment Group

Quetzaltenango, Guatemala: Jan 1999-Dec 2001

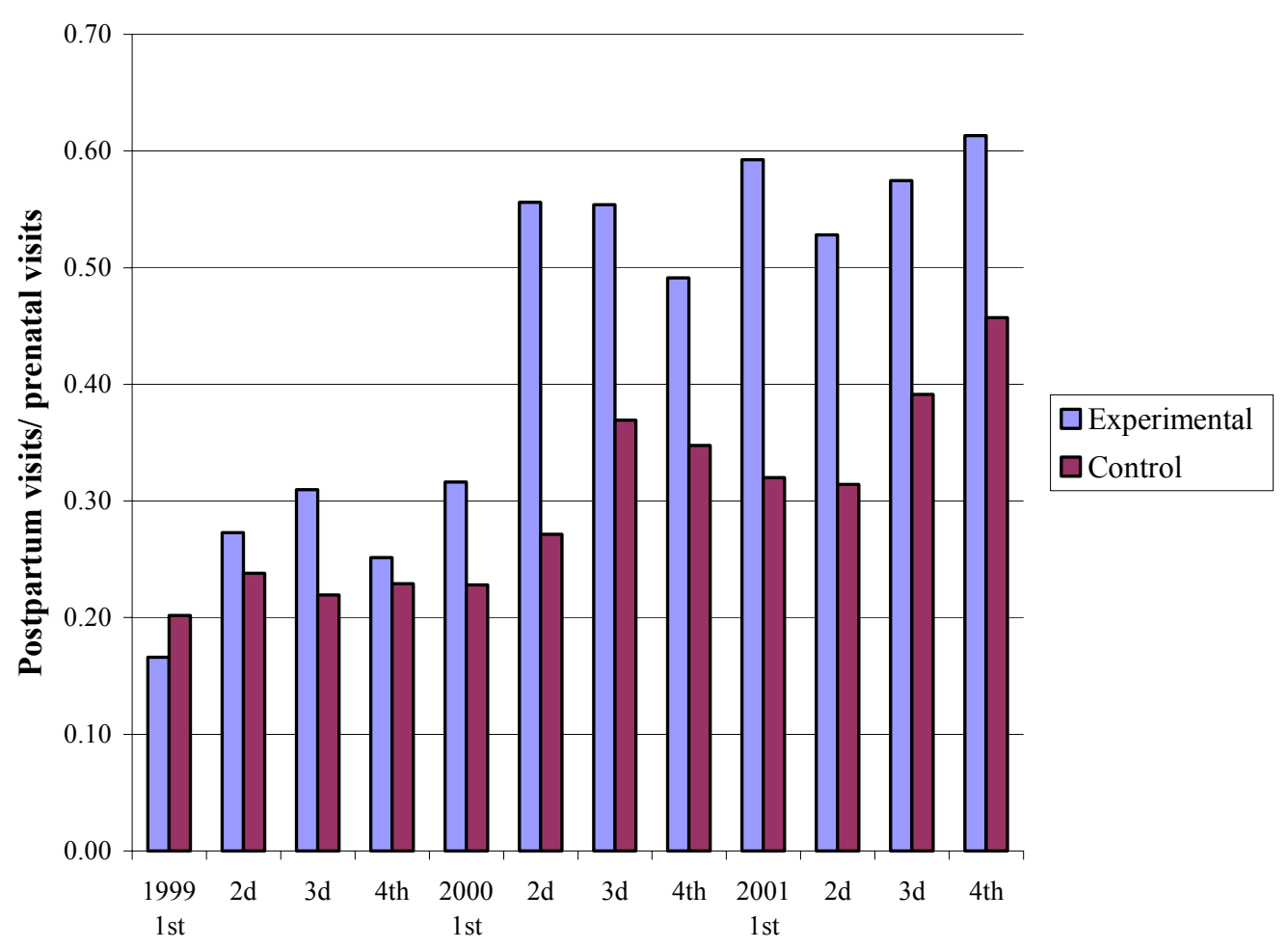

Source: Institutional service statistics. MSPAS, SIGSA 6:1999-2001, provided by the Quetzaltenango Health Area.

Graph 3 shows that the proportion of postpartum visits over registered children increased from .16 to .33 over the period from January 1999 to December 2001 in the experimental group and from .1 to .38 in the control group. Although the experimental group showed a higher proportion of postpartum visits per registered child at the start of the project, Graph 3 shows that this difference increases substantially during the project period. However, at later stages of this project (year 2001), the difference between the experimental and the control groups tends to decrease, especially during late 2001. 


\section{Graph 3 \\ Postpartum Visits/ Number of Registered Children During Same Quarterly Period per Treatment Group Quetzaltenango, Guatemala: Jan 1999-Dec 2001}

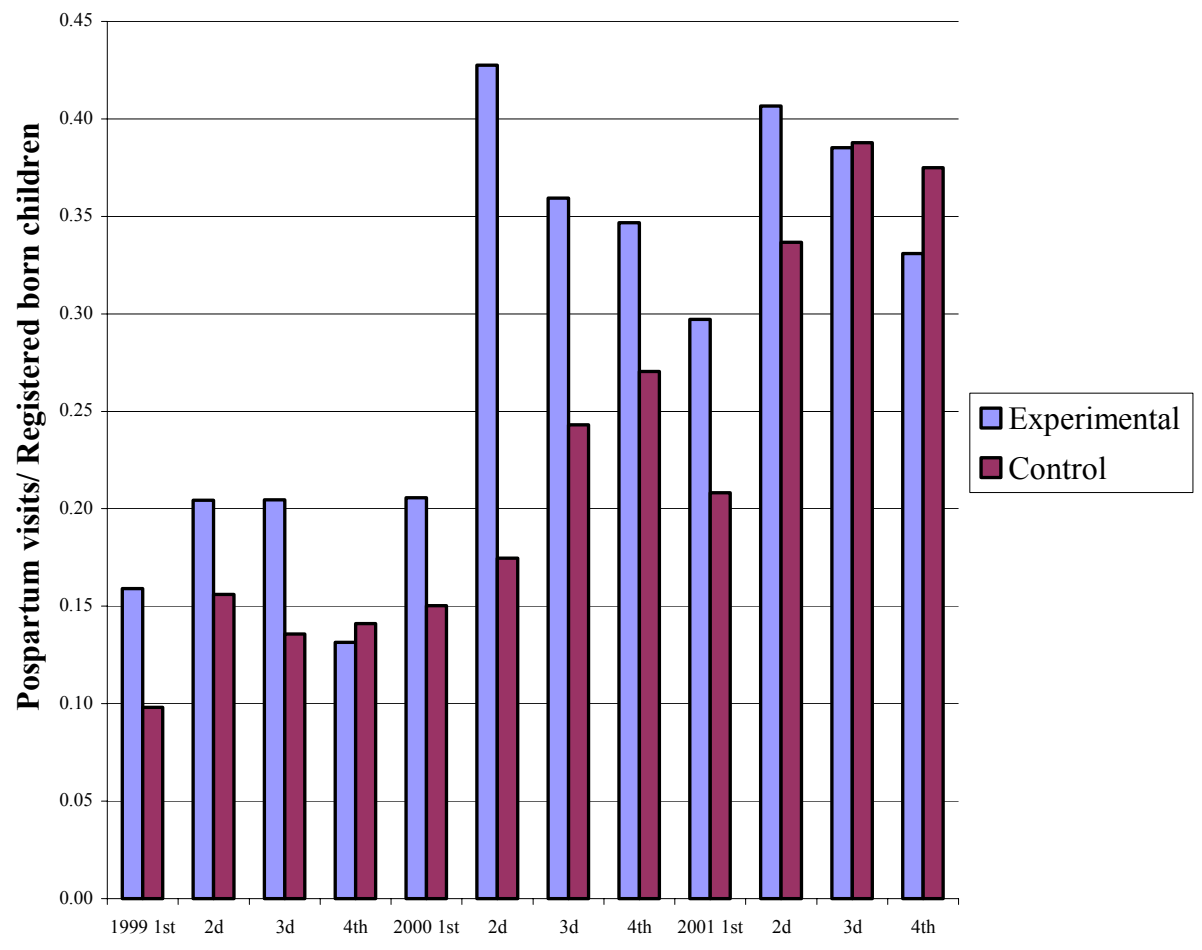

Source: Institutional service statistics. MSPAS, SIGSA 6:1999-2001, provided by the Quetzaltenango Health Area.

A final indicator to assess the degree to which service providers were able to motivate women to return for postnatal services was derived from the proportion of women in the exit interviews who reported having attended prenatal health care in the health center or post in which she was interviewed. If service providers were able to motivate women during prenatal care to return for a check-up after birth, we should expect in the endline a larger proportion of women reporting they had attended prenatal health care at the same health center or post than in the baseline. Such impact could only be observed among health posts, where the proportion of women reporting having received care at the same post increased from 11.0 percent in the baseline to 18.8 percent in the endline, among the experimental sites. This proportion also increased among control sites (from 5\%t to 14.5\%), but to a lesser degree than experimental sites. Improvement at the experimental posts was statistically significant. At health centers, there were no statistically significant changes between groups and periods, remaining at approximately 47 percent.

\subsection{Impact on Utilization of Services and Comprehensiveness of Care}

An important project objective was to make recent mothers aware of the need to attend health services postpartum and to request care, not only for the baby, but also for themselves, and to have service providers screen for health needs of recent mothers and to provide the services they needed. 
Before the intervention, 20.5 percent of the women in both the experimental and control groups declared that the main reason for attending the health center or post that day was to receive services for herself, or for both herself and the baby. After the intervention, this proportion increased to 22.8 percent in the experimental group and decreased to 19.4 percent in the control group. These changes were statistically significant.

In addition, women were asked who (themselves and/or their children) had received services during their visit the day of the interview. Table 5 shows that the proportion of women who received services for themselves during their visit increased in the experimental group from 22.8 percent in the baseline survey to 29.5 percent in the endline survey, compared to a slight increase from 22.4 percent to 24.2 percent in the control group, a result that suggests that either a greater proportion of women sought services for themselves or the providers screened the health needs of mothers to a larger extent. Observed changes are statistically significant.

Table 5

\section{Proportion of Women Interviewed who Received Services During their Visit to the Health Center or Post, by Group and Survey Quetzaltenango, Guatemala: Jan 1999-Dec 2001}

\begin{tabular}{|l|r|r|r|r|r|}
\hline & \multicolumn{2}{|l|}{ Experimental } & \multicolumn{2}{|c|}{ Control } & \\
\hline $\begin{array}{l}\text { Person who } \\
\text { received the } \\
\text { service }\end{array}$ & Before & After & Before & After & Total \\
\hline Baby only & 76.1 & 66.7 & 74.7 & 75.3 & 73.2 \\
\hline Mother only & 6.7 & 11.8 & 8.4 & 7.0 & 8.5 \\
\hline $\begin{array}{l}\text { Baby and } \\
\text { mother }\end{array}$ & 16.1 & 16.7 & 14.1 & 15.4 & 15.7 \\
\hline None & 1.1 & 4.9 & 2.7 & 2.2 & 2.6 \\
\hline Total & 100.0 & 100.0 & 100.0 & 100.0 & 100.0 \\
\hline N & 535 & 390 & 297 & 227 & 1449 \\
\hline
\end{tabular}

A comparison between first time and subsequent visits shows non-significant variations. Integrated attention provided to mothers and children in the same visit proved to be more frequent among first-time visits than subsequent visits. The proportion of first-time visits receiving comprehensive mother-child care increased from 14.3 percent in the baseline to 22.3 percent in the endline, among the experimental sites. This proportion increased only from 14.5 percent to 17.3 percent among the control sites. However, these differences are not statistically significant.

Greater comprehensiveness of care should also be reflected in an increasing number of women receiving at least one service for themselves (that is, in addition to care provided to the baby) during their visit and a greater mean number of services. Survey results show that the proportion of women receiving at least one service for themselves increased from 22.9 percent in the baseline to 32.0 percent in the endline among the experimental group. This proportion remains unchanged at 25 percent among the control sites. Improvement among the experimental sites was statistically significant $(\mathrm{p}<.05)$. No statistical differences between first-time visits and subsequent visits were observed. 
Table 6 shows the type of preventive services (including, in this case, services provided to both mother and/or baby) provided in the visit of the day of the interview to 388 women who were attending the health center or post for the first time after the birth of their child. Note that these services may or may not be provided in addition to care for the illness of the mother or the baby, which is the main reason for visiting medical units. As can be seen, the proportion of women and children who received preventive health services increased in both intervention and control units. In the case of family planning services, an increase from 3.8 percent to 7.3 percent was observed in the experimental group, compared to a decrease from 5.3 percent to 3.7 percent in the control group.

Table 6

Services Received by Women Visiting the Health Center or Post for the First Time After the Birth of the Child, by Group and Survey Quetzaltenango, Guatemala: Jan 1999-Dec 2001

\begin{tabular}{|c|c|c|c|c|c|}
\hline Postnatal & \multicolumn{2}{|c|}{ Experimental } & \multicolumn{2}{|c|}{ Control } & \multirow[b]{2}{*}{ Total } \\
\hline $\begin{array}{l}\text { Services } \\
\text { received }\end{array}$ & Before & After & Before & After & \\
\hline Postnatal care & 2.8 & 15.3 & 1.3 & 8.5 & 7.7 \\
\hline $\begin{array}{l}\text { Family } \\
\text { planning }\end{array}$ & 3.8 & 7.3 & 5.3 & 3.7 & 5.2 \\
\hline Pap smears & 0.0 & 0.8 & 0.0 & 0.0 & 0.3 \\
\hline Tetanic toxoid & 2.8 & 4.0 & 6.6 & 2.4 & 3.9 \\
\hline Well child care & 2.8 & 8.1 & 9.2 & 3.7 & 5.9 \\
\hline Vaccinations & 49.1 & 58.9 & 48.7 & 62.2 & 54.9 \\
\hline $\begin{array}{l}\text { Child } \\
\text { registration }\end{array}$ & 0.0 & 10.5 & 0.0 & 13.4 & 6.2 \\
\hline $\begin{array}{l}\text { No preventive } \\
\text { services }\end{array}$ & 41.5 & 30.6 & 43.4 & 31.7 & 36.3 \\
\hline $\mathbf{N}$ & 106 & 124 & 76 & 82 & 388 \\
\hline
\end{tabular}

Table 7 shows that similar results are observed when all women interviewed are considered in terms of the services received since the birth of their child, either in the visit made during the day of the interview or in previous visits. In general terms, the proportion of women receiving preventive health services such as postnatal care, family planning services and Pap smears, increased to a higher degree in the experimental group than in the control group. All differences proved to be significant from a statistical viewpoint. 
Table 7

Proportion of Women Who Have Received Different Services at the Health Center or Post Since the Birth of their Last Child, by Group and Survey Quetzaltenango, Guatemala: Jan 1999-Dec 2001

\begin{tabular}{|c|c|c|c|c|c|}
\hline Postnatal & \multicolumn{2}{|c|}{ Experimental } & \multicolumn{2}{|c|}{ Control } & \multirow[b]{2}{*}{ Total } \\
\hline $\begin{array}{l}\text { Services } \\
\text { received }\end{array}$ & Before & After & Before & After & \\
\hline Postnatal care & 2.4 & 12.3 & 3.7 & 9.2 & 6.4 \\
\hline $\begin{array}{l}\text { Family } \\
\text { planning }\end{array}$ & 6.5 & 12.5 & 14.0 & 8.3 & 10.0 \\
\hline Pap smears & 0.0 & 1.5 & 1.3 & 0.0 & 0.5 \\
\hline Tetanic toxoid & 40.7 & 29.5 & 20.4 & 24.6 & 31.0 \\
\hline Well child care & 6.5 & 14.3 & 24.7 & 17.1 & 14.0 \\
\hline Vaccinations & 83.5 & 83.0 & 93.3 & 82.5 & 83.1 \\
\hline $\begin{array}{l}\text { Child } \\
\text { registration }\end{array}$ & 2.4 & 11.3 & 2.7 & 11.0 & 6.2 \\
\hline $\begin{array}{l}\text { No preventive } \\
\text { services }\end{array}$ & 10.0 & 11.5 & 13.0 & 12.3 & 11.4 \\
\hline $\mathbf{N}$ & 538 & 400 & 299 & 228 & 1,465 \\
\hline
\end{tabular}

In addition to seeking greater utilization and comprehensiveness of preventive health services by mothers and children, an additional objective of the interventions was to make mothers more aware of symptoms of health problems that they and their babies could experience in the first days and months after birth, and of the need to seek health services when they showed these symptoms.

Both before and after the interventions, about 20 percent of mothers in the experimental group reported having had a health problem in the first six weeks after birth, compared to a small decrease in the proportion of mothers (from $17 \%$ to $15 \%$ ) who reported a health problem in the control group. The most common problems were high fever (42.2\% of the women reporting problems), abdominal pain (39.8\%), bleeding $(18 \%)$ and convulsions (5.6\%). An additional 3.1 percent reported other problems, such as headaches, stomach pain, breast pain, and other unspecified symptoms.

Of those who declared having had a problem in the first six weeks after birth, the proportion of women in both the experimental and control group who declared having visited a physician or nurse to solve the problem increased in the endline survey from 54.2 to 62.6 percent and from 48.1 to 70.0 percent, respectively.

The proportion of women who visited a health center or post to solve the problem also increased in both the experimental (from 35\% to 46\%) and in the control group (from $31 \%$ to $59 \%$ ). In both the experimental and control groups, there was a similar increase in the proportion of those women who had a problem and who said they had received information before the problem had occurred about symptoms and what to do (from $9 \%$ to $14 \%$ in the experimental group and from $10 \%$ to $15 \%$ in the control group). Most of these women reported having received the information at the health centers and posts. 
Regarding infant health problems, mothers reported that about 26 percent of them had experienced health problems during the first six weeks postpartum, with small and non-significant differences between groups and periods. The most frequent problems reported were high fever (about one-half of the cases in the baseline), respiratory diseases (about one-fourth of the cases), other infections, and problems with the umbilical cord and skin color. In all cases, the prevalence of these problems decreased significantly between the baseline and the endline, except for miscellaneous symptoms to which the population refers to in unidentified indigenous or common terms.

In about 84 percent of the cases, the babies who had these health problems were taken to health services with medical or paramedical staff, including 50 percent who attended the health centers and posts in project areas. However, there were no significant differences between groups or between periods.

Nevertheless, the proportion of women who had been given information about the possibility of the occurrence of that particular health problem and what to do in its case increased in the experimental group from 9 to 23 percent, and from 11 to 18 percent in the control group, a significant change in both cases. In both the experimental and control groups, the proportion who received this information in the health center or post increased from about 30 percent to about 58 percent.

\subsection{Impact on Knowledge Related to Preventive Health Practices}

The interventions in both communities and health facilities required that information to make reproductive health decisions be given to women during their pregnancy and in the first months after the birth of their child.

The proportion of women who said they had heard about family planning increased after the intervention from 44.9 to 58.4 percent in the experimental group, compared to a small decrease from 62.5 to 58.5 percent in the control group, a statistically significant difference. No significant differences between groups or periods were observed when total recall of the individual contraceptive methods (unaided plus aided recall) is considered. However, the mean number of methods known by interviewees increased from 2.3 to 3.1 in the experimental group, a larger and more statistically significant increase than in the control group. In general terms, the data showed that among those who said they had heard of contraceptive methods, 97 percent had heard about pills and injectables. The IUD, condoms and female sterilization were mentioned by about 70 percent of the respondents, and male sterilization by 54.8 percent. Knowledge about the contraceptive effect of exclusive breastfeeding (LAM), increased significantly in both the experimental and control sites, from around 30 percent in the baseline to more than 40 percent in the endline. This result is important because previous studies have shown a preference among local populations for natural methods, including breastfeeding.

Women were also asked if they had received information on 15 health behaviors that the $\mathrm{MOH}$ should promote. Table 8 presents the results obtained in the baseline and endline surveys. Little differences were found between the experimental and control groups in the trends observed between the baseline and the endline. Although the 
general pattern was for increased information given, decreases in the proportion of women receiving information on selected items are also observed. If we focus on the mean number of items on which the women received information, in the experimental group this increased from 4.7 in the baseline to 4.8 in the endline, compared to a change from 4.7 to 5.1 items informed in the control group.

Regarding sources of information, the mean number of items informed increased in experimental health centers and posts, but the observed increases were greater in the control group. Information given from other agents trained in the project, such as traditional birth attendants and community volunteers, either remained the same or decreased, with no positive differences found in favor of the experimental group in comparison with the control group. In general terms, health centers and posts gave information to between 30 percent and 50 percent of the women on any given item, whereas TBAs provided information on any given item to between 15 percent and 25 percent of women in both groups and surveys. 
Table 8

Proportion of Women who Received Information on Different Health Practices During Pregnancy or in the First Days After Birth and Mean Number of Items Informed by Source of Information (Base $=15$ items), by Group and Survey.

Quetzaltenango, Guatemala: Jan 1999-Dec 2001

\begin{tabular}{|c|c|c|c|c|}
\hline \multirow[b]{3}{*}{ HEALTH PRACTICE/ITEM } & \multicolumn{4}{|c|}{ GROUP } \\
\hline & \multicolumn{2}{|c|}{ Experimental } & \multicolumn{2}{|c|}{ Control } \\
\hline & Baseline & Endline & Baseline & Endline \\
\hline \multicolumn{5}{|c|}{ Proportion of women informed about preventive practices } \\
\hline When to start breastfeeding & 33.3 & 22.8 & 26.1 & 29.8 \\
\hline How long to breastfeed & 32.0 & 21.0 & 25.4 & 33.8 \\
\hline $\begin{array}{l}\text { How to care for breast while } \\
\text { breastfeeding }\end{array}$ & 17.7 & 24.8 & 18.1 & 32.9 \\
\hline How to treat breasts & 14.3 & 16.0 & 13.0 & 25.9 \\
\hline How to clean genitalia & 30.7 & 28.8 & 17.1 & 28.5 \\
\hline Mother's danger signs & 8.4 & 15.0 & 8.0 & 16.2 \\
\hline Rest during first 4 weeks & 50.2 & 43.3 & 49.2 & 40.4 \\
\hline When to resume sex & 17.5 & 31.3 & 25.8 & 36.0 \\
\hline Child danger signs & 10.2 & 15.8 & 10.0 & 18.4 \\
\hline Nutrition & 43.9 & 39.5 & 49.5 & 39.2 \\
\hline $\begin{array}{l}\text { How to care for baby's umbilical } \\
\text { cord }\end{array}$ & 36.1 & 44.5 & 39.1 & 39.6 \\
\hline Need to cover baby & 25.7 & 34.2 & 21.7 & 32.0 \\
\hline General baby care & 24.0 & 35.0 & 21.1 & 35.5 \\
\hline Vaccination regime & 65.8 & 64.1 & 71.9 & 59.5 \\
\hline $\begin{array}{l}\text { Need to visit HC for well baby } \\
\text { care }\end{array}$ & 57.8 & 43.6 & 53.5 & 44.7 \\
\hline \multicolumn{5}{|c|}{ Mean number of items informed by source of information } \\
\hline MOH HC/HP & 1.5 & 1.6 & 1.0 & 1.8 \\
\hline TBA & 1.8 & 1.4 & 1.3 & 1.5 \\
\hline Other sources & 1.3 & 1.8 & 2.1 & 2.1 \\
\hline Total & 4.7 & 4.8 & 4.7 & 5.1 \\
\hline Standard deviation of total & 3.7 & 4.4 & 3.5 & 4.4 \\
\hline $\mathbf{N}$ & 538 & 400 & 299 & 228 \\
\hline
\end{tabular}

\subsection{Impact on Preventive Health Behaviors}

In this section we assess if the interventions had any impact on the preventive health practices of women that were interviewed in the baseline and endline surveys.

Regarding lactation, a survival analysis showed that the proportion of women who started breastfeeding their babies on the first day after birth changed only slightly from 77.5 percent to 75.5 percent in the experimental group and from 84.6 percent to 83.3 percent in the control group. The project did not seem to have any effect on the duration of exclusive breastfeeding, since the proportion of women who exclusively breastfed their children at six months declined both in the experimental and in the control group, from 25.9 to 17.3 percent and from 22.7 to 18.3 percent, respectively. 
The median duration of exclusive breastfeeding changed from 4.92 to 4.32 in the experimental group, and remained approximately constant at 4.63 in the control group.

Regarding contraceptive use, the proportion of women using a method three months after birth increased from 18.1 percent in the baseline in the experimental group to 24.7 percent in the endline, compared to a decrease from 20.4 to 14.3 percent in the control group. Very importantly, the proportion of women starting use of contraceptives during the puerperal period (less than 40 days) increased from 3.1 to 15.6 percent in the experimental group, while it remained approximately constant in the control group at 10.0 percent. The proportion of women using contraceptives after the puerperal period and before three months postpartum increased from 6.9 percent to 19.4 percent among the experimental group and reduced from 23.0 to 15.4 percent in the control group. These changes are statistically significant.

A survival analysis shows that about one-fourth of those using contraceptives began using their method in the first month after birth. By the second month, 58.8 percent of the current contraceptive users were already using a method, and by the third month 70.1 percent had requested a method. By the fifth month postpartum, 84.8 percent of contraceptive users were already using the method, and at six months, 90.2 percent had adopted the method. No significant changes were observed between periods and groups.

Nearly 65 percent of women received their method from the health center or post and no statistically significant changes were observed in this respect. Likewise, although the proportion of women using their preferred method increased from 80.3 to 89 percent in the experimental districts and the proportion remained constant in control sites, the observed differences were not significant. Of the 16.3 percent who said they were not using their preferred method, most said they would like to use Depo-Provera $(44 \%)$ or the IUD $(24 \%)$.

Regarding unmet need for contraception, 87.9 percent of the women interviewed said they would not want to get pregnant in the next year. Of these, only 12.4 percent were using a method. Contraceptive prevalence increased from 11.1 to 13.4 percent in the experimental group, and reduced from 16 to 9.4 percent in the control group. The improvement observed in the experimental group is statistically significant.

Experimental group health centers and posts seemed to have made a larger effort to reduce unmet need, since the proportion of women who reported having been offered methods increased from 37.6 to 52.5 percent in the experimental group, and from 30.8 to 40.4 percent in the control group. The results also showed that 88 percent of the women said they were interested in learning more about contraceptives. This proportion remained constant in both groups and over time.

Regarding other reproductive health preventive services, the results showed that:

1) The proportion of women who had received two anti-tetanus shots during pregnancy or after the birth of the child was about 77 percent in both groups, and no significant changes between groups were observed. 
2) Only about one half of the women had heard of the Pap test and less than 20 percent of these had ever had a test. The proportion of women who had had a Pap test in the last year increased moderately in both the experimental (from 2.6\% to $4.5 \%$ ) and in the control group (from 3.7\% to $5.3 \%$ ). The proportion who received information about Pap smears at the health center increased more substantially, from 17.8 to 38.7 percent in experimental group outlets and from 18.6 to 29.5 percent in control group health centers and posts.

3) The proportion of women who said that they knew how to do a breast self-examination to detect cancer nearly doubled between the baseline and endline surveys, but remained very low in both the experimental group (7.8\%) and in the control group (9.6\%).

4) Only about 20 percent of the women said they had heard of STDs, and only about one-fourth of these were able to mention at least one symptom of an STD. Likewise, only about 37 percent of those who had heard of STDs mentioned use of the condom as a way to prevent them. Information giving practices about STDs did not change either at the experimental or control sites.

5) Compliance with immunization schemes of children was high and tended to increase between the baseline and endline surveys. However, these increases were similar in the experimental and control groups. The proportion of children 9-12 months old receiving the complete three-shot schedule of DPT increased from 72.8 percent to 77 percent in the experimental group, and from 69.5 to 76.7 percent in the control group. The proportion of children receiving full Polio protection increased from 64.1 to 78.7 percent in the experimental group, while it remained at a constant 70 percent in the control group. Finally, BCG coverage at 6 months showed a decline from 94.4 to 85.9 percent in the experimental districts, and from 91 to 89.2 percent in the control districts.

\subsection{Information Received on Danger Signs}

One of the main objectives of this project was to increase the proportion of women seeking emergency health care in cases when they or their babies show danger signs. In terms of the interventions conducted, this required that health service providers promote these behaviors by giving information to women on when and how to act according to the presence of signs or symptoms after delivery which indicated the need for urgent medical care.

Table 9 shows that after the interventions there were higher increases in the experimental than in the control group in the proportion of women who mentioned fever, abundant bleeding and blood clots as emergency signs, whereas the increase in the proportion of women who mentioned strong lower abdominal pain was larger in the control group. 
Women were asked about danger signs indicating the need for urgent care for the baby in general terms, and in the case of diarrhea and respiratory infections. The results showed that mothers were more aware of danger signs for babies than for themselves. In the case of general emergency signs, only 19.7 percent of the women failed to mention at least one danger symptom.

Similar results were observed when women were asked about danger signs in babies. The average number of items known about any child emergency sign reduced from 2.33 to 1.88 in the experimental group and from 1.99 to 1.57 among the control group. The decline was statistically significant, but there are no clear explanations for such a trend other than the lack of salience with increasing time postpartum. Knowledge of diarrhea or respiratory infection-related symptoms showed similar unexpected variations. The most commonly known symptoms about respiratory diseases include fever $(43.7 \%)$, and rapid breathing. The most common symptoms known about diarrhea are dry mouth $(39.9 \%)$, baby stops eating (29.3\%), frequent vomiting $(30.9 \%)$ and tearless crying $(13.5 \%)$. These proportions remained unchanged after the intervention both in the experimental and control groups.

Finally, women were asked if they knew how to prepare oral rehydratation liquid. Over one-half of the women were able to correctly describe the procedure. This proportion increased to 57.5 percent in the experimental sites, and reduced to 42.9 percent in the control sites. Observed differences after the intervention were statistically significant. 
Table 9

Knowledge of Postpartum Danger Signs (Mother and Baby) Among Recent

Mothers Attending Health Centers and Posts

Quetzaltenango, Guatemala: Jan 1999-Dec 2001

\begin{tabular}{|c|c|c|c|c|c|}
\hline \multirow{3}{*}{$\begin{array}{l}\text { SYMPTOM/ } \\
\text { RECOMMENDATION }\end{array}$} & \multicolumn{4}{|c|}{ GROUP } & \multirow[b]{3}{*}{ Total } \\
\hline & \multicolumn{2}{|c|}{ Experimental } & \multicolumn{2}{|c|}{ Control } & \\
\hline & Baseline & Endline & Baseline & Endline & \\
\hline Fever & 29.9 & 42.5 & 30.8 & 35.5 & 34.4 \\
\hline Abundant bleeding & 17.3 & 27.8 & 20.1 & 27.2 & 22.3 \\
\hline Large blood clots & 1.5 & 4.0 & 4.0 & 3.9 & 3.1 \\
\hline $\begin{array}{l}\text { Strong lower } \\
\text { abdominal pain }\end{array}$ & 21.4 & 21.5 & 11.4 & 23.2 & 19.7 \\
\hline $\begin{array}{l}\text { Mean number of } \\
\text { symptoms mentioned }\end{array}$ & .72 & 1.01 & .72 & .98 & .84 \\
\hline $\begin{array}{l}\text { Recommended to } \\
\text { attend } \mathrm{HC} \text { in case or } \\
\text { symptoms }\end{array}$ & 12.8 & 25.8 & 11.7 & 36.0 & 19.7 \\
\hline $\begin{array}{l}\text { Mean number of } \\
\text { general symptoms } \\
\text { showing babies need } \\
\text { urgent medial care } \\
\text { mentioned }\end{array}$ & 2.33 & 1.88 & 1.99 & 1.57 & 2.02 \\
\hline $\begin{array}{l}\text { Mean number of } \\
\text { emergency symptoms } \\
\text { during diarrhea } \\
\text { mentioned }\end{array}$ & .74 & .62 & .61 & .52 & .65 \\
\hline $\begin{array}{l}\text { Mean number of } \\
\text { emergency symptoms } \\
\text { during respiratory } \\
\text { infections mentioned }\end{array}$ & .81 & .77 & .80 & .70 & .80 \\
\hline $\begin{array}{l}\text { Proportion who } \\
\text { correctly described } \\
\text { how to prepare oral } \\
\text { rehydration fluid }\end{array}$ & 55.9 & 57.5 & 56.5 & 48.2 & 55.3 \\
\hline Total Number of Cases & 538 & 400 & 299 & 288 & 1465 \\
\hline
\end{tabular}

Source: Baseline and endline exit interviews. Postpartum Xela Project. September 1999 and September 2001. FRONTIERS, Guatemala.

\subsection{Impact on Knowledge, Attitudes and Practices of Providers}

The surveys of service providers sought to assess if, as a consequence of the interventions, they improved their understanding of and attitudes towards integrated health care for mothers and children, and if their knowledge and delivery of reproductive health services improved. These issues are discussed below. 


\section{Exposure to the Intervention}

According to survey results, the proportion of service providers receiving training on maternal and child care during the past year increased from 38.5 to 77.4 percent among the experimental sites and decreased from 59.4 to 17.2 percent among control sites. This is consistent with activities conducted by MotherCare during the previous years. The MotherCare program finished in June 2000, and this postpartum project remained as the sole initiative to train service providers on maternal and child care.

Topics covered during training include contraceptive methods, family planning counseling and natural methods (LAM). More than 90 percent of providers who have been trained reported having received training on these topics. Proportionally fewer service providers received training on administration (average of $27 \%$ before and after the intervention), supervision (50\%), registration procedures $(85 \%)$ and logistics $(78.8 \%)$.

\section{Understanding of Mother-Child Integrated Care}

Baseline and endline survey results show that the intervention had a significant impact on the understanding of the concept of mother-child integrated attention. In the baseline survey, 79.5 percent of providers in the experimental group and 72.7 percent in the control group could correctly describe what mother-child integrated attention entailed. After the intervention, this increased to 94.3 percent in the experimental sites and to 86.2 percent in the control sites, a statistically significant difference. Elements frequently offered in service provider responses included joint attention as a strategy to reduce missed opportunities, the educational aspect of mother-child joint attention and, the idea of joint care as an opportunity for providing preventive health care to both mother and child when they are attending health facilities for illness.

The intervention also made service providers aware of the opportunities that are usually missed to provide joint maternal and child care. Before the intervention, 2.6 percent of providers in experimental districts and 6.1 percent of providers among control districts claimed that no opportunities were lost at their health units to provide services to children and mothers. After the intervention, such proportions increased to 7.5 percent and 17.2 percent respectively.

As a result of the intervention, a greater proportion of providers knew how opportunities to provide health services were missed and what were the advantages of providing integrated health care. Prior to the intervention, 43.6 percent of providers at experimental sites and 36.3 percent at control sites acknowledged that opportunities were missed when they provided single service attention, or when they responded only to the service requested by clients. This proportion increased to 50.9 percent among the intervention sites, and remained unchanged at 33 percent among control sites. Likewise, prior to the intervention, 19.9 percent of providers at intervention sites and 27.2 percent at control sites were unaware of any advantages of providing joint attention to mothers and children. These proportions were reduced to 2 percent in the experimental group and to 6.4 percent in the control group. Some of the advantages more frequently 
mentioned by service providers were the improved coverage of services and the reduction of maternal and child morbidity and mortality.

After the intervention, the proportion of providers who did not perceive obstacles to providing integrated health care services increased. Prior to the intervention, 41 percent of providers at intervention sites and 36.4 percent at control sites did not perceive obstacles, whereas after the intervention, these proportions increased to 45.3 percent and 41.6 percent respectively, a statistically significant difference. Among those who perceived obstacles, the most frequently mentioned were lack of resources and client resistance to receive more services than the one they requested. Both of these reasons were more frequently mentioned in the endline than in the baseline survey. However, the proportion of respondents mentioning institutional barriers to integrated service provision declined in both groups from over 20 percent to about 3.5 percent.

Regarding the lack of demand for postpartum services, in the baseline survey over 20 percent of the providers identified lack of interest from clients as the cause and client education as the solution for this problem. Only 8 percent identified training of providers as a feasible solution. Whereas the percent in the control group remained the same in the endline survey, the proportion in the experimental group who identified training of service providers as a solution to the problem increased to 21 percent.

\section{Screening, Information and Counseling Practices}

Attitudes and practices related to screening for patients needs, information giving, and counseling during pregnancy and the first year postpartum were assessed in the baseline and endline surveys to determine if the training provided had achieved any changes.

Regarding prenatal care, providers were asked what they should inform a woman in the third trimester. A total of six items were explored. In both surveys, nearly all providers mentioned the six items: situations in which the woman should seek emergency medical care, how to care for herself during pregnancy, how and for how long to breastfeed the baby, how to properly care for the baby, vaccinations and immunizations, and contraceptive methods to space the next birth.

Concerning the first 40 days of the postpartum period, the questionnaire explored screening and information-giving practices (including information on symptoms in mothers and in children, recommendations for mother and children, emergency plan, involvement of family and neighbors). The results demonstrate that the project had only a small impact on the saliency of a few behaviors of service providers. Differences between groups and between periods are usually small, and some critical elements of care that the project wished to change remained at low levels.

\section{Knowledge of Danger Signs and Symptoms}

An additional project objective was to train providers to identify danger signs in women in the postpartum period and of diarrhea and acute respiratory infections in children under one year of age. Providers were asked to list signs and symptoms that 
showed the need for urgent medical care in these conditions. For women in the postpartum period, the questionnaire listed a total of seven signs. For diarrhea, eight signs were listed, and for respiratory infections, 10 danger signs were listed. Results showed that providers in the experimental group mentioned a larger number of symptoms in the endline survey than providers in the control group, as well as that a greater improvement in the number of items mentioned was observed. However, these improvements were relatively modest.

\section{Knowledge of Other Preventive and Reproductive Health Services}

A final section of the questionnaire explored changes in the providers' knowledge related to reproductive and preventive health services, including knowledge of contraceptive methods (providers were asked to mention the contraceptives they knew of) and of their contraindications (providers were asked if a given condition was an absolute or relative contraindication for a given method), knowledge of the number of immunization doses mothers and babies need, knowledge of cancer prevention practices, and knowledge of STD symptoms and ways to avoid STDs. As in the case of the previous scales, only small improvements were observed between the baseline and endline surveys, though these were found more frequently in the experimental than in the control group.

\section{CONCLUSIONS AND RECOMMENDATIONS}

The purpose of this project was to test different materials and strategies to increase the proportion of women who receive health services in the first year after the birth of a child and to improve the quality of care they receive, particularly in terms of the constellation of services. To achieve these objectives, the project developed and tested a manual and job aids, and trained physicians, nurses, auxiliary nurses and social workers in their use. The project also developed materials and promotional strategies, and trained community health agents in their use and implementation.

Concerning the impact on the volume of services offered at institutional facilities, service statistics showed that the number of postnatal visits increased 46 percent in experimental sites with respect to the corresponding period in the previous year (2000), and that this increase became noticeable immediately after the intervention occurred. However, the number of postnatal visits in the control group also increased, with a one-month lag, which suggests contamination of the intervention in control group indicators or the confounding effect of other interventions, such as training conducted by the Calidad en Salud program.

Regarding contraceptive use, the proportion of women using a method three months after birth increased from 18.1 percent in the baseline in the experimental group to 24.7 percent in the endline, compared to a decrease from 20.4 to 14.3 percent in the control group. Very importantly, the proportion of women starting use of contraceptives during the puerperal period (less than 40 days) increased from 3.1 to 15.6 percent in the experimental group, while it remained approximately constant in the control group at 10.0 percent. The proportion of women using contraceptives after the puerperal period and before three months postpartum increased from 6.9 percent to 19.4 percent among 
the experimental group and reduced from 23.0 to 15.4 percent in the control group. These changes are statistically significant.

A survival analysis shows that about one-fourth of those using contraceptives began using their method in the first month after birth. By the second month, 58.8 percent of the current contraceptive users were already using a method, and by the third month 70.1 percent had requested a method. By the fifth month postpartum, 84.8 percent of contraceptive users were already using the method, and at six months, 90.2 percent had adopted the method. No significant changes were observed between periods and groups.

The ratio of postpartum visits over prenatal visits increased 2.7 times among the experimental sites over the 18-month project period, as compared to an increase of 1.3 times observed among the control sites (Graph 2). This indicated that women who had attended prenatal care at a health center or post were also more likely to return to postnatal care after the project.

Results also showed that a greater proportion of women sought preventive services for themselves in the experimental group than in the control group, and that services received by women at intervention sites were more diverse than at control sites

However, when improvements were observed, they tended to be rather modest (at least in terms of expectations), and in several cases, such as for the amount of information received or remembered on different health issues, the improvements observed in the experimental group were not larger than those observed in the control group.

Several factors may account for these results. The first of these factors is the possible contamination of the control group, due to communication between experimental and control service providers, since the Health Area of Quetzaltenango conducts monthly meetings to discuss problems and progress made in project implementation. A second possible factor was the confounding effects of other training and interventions implemented by the Calidad en Salud project to improve the quality of care in $\mathrm{MOH}$ services nationwide. A third possible factor is the long time span between the training of institutional service providers and the actual evaluation. Usually, evaluation of training is conducted three or four months after the event. In this case, more than a year passed between in-service training and the endline measurement. Finally, a fourth factor that affected the referral and counterreferal system tested in this project were changes in the functioning of the primary level of care in Guatemala. During recent years, the Government of Guatemala began implementing an Integrated System for Health Care (known by its acronym in Spanish, SIAS) that seeks to extend coverage to previously underserved areas through subcontracts with NGOs. In Quetzaltenango, the SIAS has made important structural changes that have increased the coverage and quality of services, and these changes could not have been anticipated when this study was designed. 


\section{NOTES.}

\footnotetext{
${ }^{\mathrm{i}}$ Safe Motherhood Newsletter. Issue 13. November 1993 - February 1994. Pps 4-6.

${ }^{i i}$ Nancy Sloan, personal communication. In one project in Nepal, Vitamin A given in the post-partum helped reduce mortality by $43 \%$ by reducing infections and improving tissue integrality. It also reduces fetal ocular problems and maternal blindness.

iii Mother Care Matters. Micronutrients for the Health of Women and Newborns. Volume 6, No 1. November/December, 1996. According to Nancy Sloan (personal communication), iron improves hemoglobin levels, although low compliance with regimes has been observed in most projects; folic acid reduces anemia; calcium reduces pre-eclampsia, hypertension; and zinc has a theoretical but unproved positive effect.

iv Venguer, Tere; G. Fawcett, R. Vernon and Susan Pick. 1998. Violencia doméstica. un marco conceptual para la capacitación del personal de salud. Documento de trabajo Número 24, México, D.F., INOPAL III, Population Council
}

${ }^{v}$ Ross, John A and W.L. Winfrey. Contraceptive use, intention to use and unmet need during the extended postpartum period. International Family Planning Perspectives. 2001 Mar; 27(1):20-7.

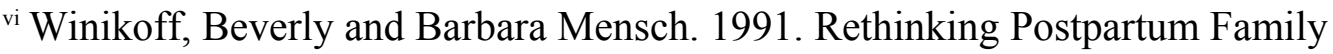
Planning. Studies in Family Planning 22, 5: 294-307.

vii Ministerio de Salud Pública y Asistencia Social. Carnet de Vacunación. 1998. Guatemala

viii See Ministerio de Salud Pública y Asistencia Social. Normas de Atención. Guatemala, Diciembre 1997; Ministerio de Salud. Normas de Atención a la Mujer. Honduras, Noviembre 98; Secretaría de Salud. Normas para la Atención del Embarazo, Parto y Puerperio. México, 1994; y ...Nicaragua.

${ }^{\text {ix }}$ Maternal-Child Health Survey, Guatemala

${ }^{\mathrm{x}}$ Information provided personally by the MOH Area staff. It should be considered that coverage of immunization includes immunizations provided during campaigns in communities and convergence centers.

${ }^{x i}$ Along the project period, one Health District was divided into two Districts. 